\title{
CONSTITUCIÓN DE UN SINDICATO DE DOCENTES EN UNA INSTITUCIÓN DE EDUCACIÓN SUPERIOR
}

\section{Proceso de constitución y negociación}

La idea de constituir un sindicato de docentes de la Universidad Austral de Chile nació hace algunos años. En diversas oportunidades la directiva de la Asociación Gremial de Académicos presentó la idea a la asamblea, la cual, en forma casi unánime, rechazó la propuesta argumentando que no era propio de académicos pertenecer a un sindicato, probablemente por su habitual connotación política y confrontacional.

En los últimos años y con distintos rectores la Asociación Gremial no fue escuchada en sus peticiones. Las autoridades no consideraban su opinión ni acogían sus demandas. Incluso, en varias ocasiones, la autoridad no respetó los acuerdos ni las reuniones fijadas con la debida anticipación.

Este desconocimiento permanente hizo pensar a la directiva de la Asociación Gremial en la necesidad de tener una organización con respaldo legal y regulada y reglamentada por un organismo externo a la universidad.

Su primera tarea consistió en conocer la forma como funcionan los sindicatos, las diferencias entre un sindicato y una asociación gremial y sus respectivas ventajas. Colaboraron con información el Sindicato de Funcionarios de la Universidad Austral de Chile (UACh), la Inspección del Trabajo y abogados.

La principal ventaja del sindicato es que se trata de una organización regulada por un marco legal establecido en el Código del Trabajo y con derecho a negociar colectivamente, lo que asegura a 
los trabajadores plazos claros para obtener respuesta a sus solicitudes. También otorga derecho a realizar asambleas al interior de la empresa para tratar temas de interés para sus asociados.

Se alcanzó la convicción de que la formación de un sindicato de docentes era la única forma de lograr que las autoridades atendieran las demandas. Como en la universidad ya existía un sindicato, se requería la firma del $10 \%$ del total de funcionarios para formar uno nuevo. Dado que la intención era que estuviera constituido sólo por docentes, 180 profesores debían firmar ante el ministro de fe de la Inspección del Trabajo.

Fue necesario entonces redactar los estatutos y, simultáneamente, informar y convencer a los docentes de la necesidad de tener una organización regulada por un marco legal claro. Para lo primero se usó la experiencia de otros sindicatos más un formato tipo que proporcionó la Inspección del Trabajo. La segunda tarea era la más difícil, por los fallidos intentos anteriores por formar una organización de este tipo y la poca disposición de los docentes de esta universidad para conceder un poco de tiempo a tareas diferentes de sus actividades académicas.

Se desarrolló entonces una estrategia comunicacional que consistió en enviar información por correo electrónico a todos los académicos, junto con un afiche diseñado especialmente, el que, además, se colocó en lugares estratégicos en los tres campus de la universidad; se publicó una entrevista en el diario local y, por último, se realizó un "puerta a puerta" en el cual se conversó con una gran cantidad de docentes.

Fue un gran esfuerzo en el que hubo apoyo permanente del sindicato de funcionarios y de sus asociados, no así de las autoridades, quienes siempre pensaron que no se lograría el cometido.

Luego de la campaña, se fijó el 11 de julio de 2007 como fecha para la constitución. Había temor de no poder alcanzar tan sentida aspiración. Ese día se invitó constantemente a los profesores 
a participar y toda la comunidad universitaria estaba pendiente de este hecho inédito en el sistema universitario chileno.

El recuento de firmas realizado por la ministra de fe de la Inspección del Trabajo confirmó la constitución del Sindicato de Docentes de la UACh con 311 adherentes. Probablemente, este resultado se debió a que los docentes, cansados de que sus demandas no fueran atendidas, se convencieron de que la única forma de obtener respuesta por parte de las autoridades era por medio de una organización amparada y regulada por el Código del Trabajo.

De acuerdo con lo establecido en este Código, en el acto de constitución del sindicato se llevan a cabo dos votaciones: una que aprueba o rechaza su constitución y otra en la cual se elige la primera directiva. En esta última instancia, todas las personas con derecho a participar son elegibles y el número de integrantes de la directiva depende de la cantidad de personas que constituyan el sindicato. De acuerdo con estos resultados, la directiva se formó con cinco dirigentes quienes, inmediatamente, determinaron los cargos y empezaron a trabajar en la formulación del plan de trabajo.

Se planteó presentar una propuesta de negociación colectiva en octubre, para lo cual se definieron los objetivos de la negociación y se formaron comisiones para trabajar los aspectos principales.

Una vez definida la propuesta, se contrató un asesor experto en esta clase de negociaciones, el que ayudó a dar la forma definitiva al proyecto y apoyó a la directiva durante todo el proceso de negociación. Este documento se sometió a la asamblea y, luego de acoger las sugerencias, fue presentado a las autoridades en octubre de 2007. El sindicato contaba ahora con 360 socios. Entonces, empezaron a alcanzarse los plazos establecidos en la ley, los que se cumplieron a cabalidad.

La universidad respondió negativamente a todo el petitorio, algo usual en toda negociación, según el asesor. Después de eso, las conversaciones se prolongaron hasta mediados de diciembre. 
A medida que avanzaba el proceso de negociación se incorporaban más docentes al sindicato y la convocatoria a las asambleas aumentaba. Esto sorprendió a las autoridades de la UACh, toda vez que la Asociación Gremial nunca había reunido tantos adherentes. No obstante, al comienzo no se obtenía nada de lo solicitado, probablemente debido a que las autoridades confiaban en que los docentes no se atreverían a votar la huelga y aceptarían lo que la universidad ofreciera, aunque distara del contenido del petitorio.

Los promotores de esta iniciativa tampoco tenían mucha confianza. Entre los docentes no existía una cultura sindical, por lo tanto, no era fácil comprender lo que significaba estar en huelga, esto es, aceptar el hecho de no poder ingresar a la universidad y dejar de lado las investigaciones y otras actividades.

Llegó el día en que las autoridades debían entregar la "última oferta", esto es, la propuesta definitiva del empleador a los dirigentes y cuya copia se deposita en la Inspección del Trabajo. De acuerdo con la ley, la última oferta debe ser votada por los socios del sindicato ante un ministro de fe de la Inspección y las alternativas eran, en este caso, aceptar la última oferta del empleador (universidad) o ir a la huelga. En este referéndum el 74\% votó a favor de la huelga, resultado que demostró a las autoridades la seriedad del movimiento; sólo en ese instante empezó realmente la negociación.

Comenzaron a presentarse entonces ofertas y contraofertas. En cada reunión se acercaban las posiciones y así se desarrolló la negociación hasta el vencimiento del plazo legal, el 15 de diciembre, día en que se alcanzó el acuerdo y se firmó "el primer Contrato Colectivo entre la Universidad Austral de Chile y el Sindicato de Docentes de la UACh".

Cada día se incorporan más docentes al sindicato (actualmente cuenta con 415 asociados). Las autoridades de la UACh siempre han afirmado que mantienen buenas relaciones con los distintos estamentos; sin embargo, con los docentes no era así. Como se 
mencionó, la decisión de formar un sindicato surgió precisamente como consecuencia de las malas relaciones y peores resultados obtenidos en las conversaciones con quienes deben tomar las decisiones.

Un sindicato es una buena opción organizativa para plantear a las autoridades las necesidades y demandas de un grupo de personas que trabajan en una institución. Se obtiene respuesta en un plazo breve y permite intercambiar posiciones y llegar a acuerdos. Una institución de educación superior no es la excepción, los académicos son también trabajadores que tienen derechos y deberes con la organización, la familia y la sociedad.

No obstante, la negociación colectiva en un sindicato de docentes de una universidad reviste peculiares características, porque las autoridades son académicos elegidos por sus pares y los cuerpos colegiados también están integrados por académicos, algunos de los cuales pertenecen al sindicato. Dada su reciente fundación, las autoridades no son parte de éste, pero en el futuro puede ocurrir que los docentes elijan como rector a un académico sindicalizado y es muy probable que la mayoría de los decanos también pertenezcan. Este hecho, inédito en el sistema universitario chileno, no está contemplado en la ley ni en los estatutos de las universidades, por lo que amerita algunas definiciones. 